Journal of Advanced Research in Fluid Mechanics and Thermal Sciences

\title{
A Numerical Prediction of Stabilized Turbulent Partially Premixed Flames Using Ammonia/Hydrogen Mixture
}

\author{
Moataz Medhat ${ }^{1,}{ }^{*}$, Mohamed Yehia $^{1}$, Adel Khalil ${ }^{1}$, Miguel C. Franco ${ }^{2}$, Rodolfo C. Rocha ${ }^{2}$ \\ Department of Mechanical Power, Faculty of Engineering, Cairo University, Giza, Egypt \\ IDMEC, Mechanical Engineering Department, Instituto Superior Técnico, Universidade de Lisboa, Lisboa, Portugal
}

ARTICLE INFO ABSTRACT

Article history:

Received 2 July 2021

Received in revised form 3 August 2021

Accepted 5 August 2021

Available online 3 October 2021

\begin{abstract}
The objective of this work is to computationally assess the performance of a carbon free ammonia-hydrogen mixture when burnt in a gas turbine like combustor. Recently, utilizing ammonia as an alternative carbon-free fuel for future power, industry applications and achieving clean energy attracted enormous interest. Pure ammonia oxidation is facing many challenges such as high NOx emissions, high ignition energy, slow reactivity and lower laminar flame speeds. Therefore, the use of ammonia/hydrogen mixture provides flame stability and increasing flame speed. In this manuscript a numerical study for a new swirl stabilized combustor for oxidizing ammonia/hydrogen mixture. Numerical two dimensional model simulations of a turbulent flame on Reynolds Averaged Navier Stokes (RANS) including a realizable k- $\varepsilon$ turbulent scheme with the aid of chemistry mechanism were performed under various conditions. Partially premixed combustion model with flame-let concept was selected and radiation effects are also considered. Validation for the predicted results showed a reasonable agreement when validated with the experimental data. The results discuss the influence of changing inlet pressure and equivalence ratio on the stability and the characteristics of unburnt $\mathrm{NH}_{3}$ and $\mathrm{NO}$ emissions. Results show that for constant operating conditions such as constant equivalence ratio of 0.8 that increasing hydrogen content resulted in increasing NO emission. Also, for constant ammonia/hydrogen concentrations, NO emissions increases with equivalence ratio then reduced at rich conditions and $\mathrm{NH}_{3}$ emissions are generally low. Equivalence ratio lower than 1.2 will be preferable to reduce the amount of unburnt $\mathrm{NH}_{3}$ formation.
\end{abstract}

Keywords:

Partially premixed; gas turbine combustion; ammonia-hydrogen mixtures; cfd; flame stability

\section{Introduction}

As climate change policies as well as the reduction of capital cost for renewable energy sources for generating power including wind, PV CSP including attempts to utilize the energy content in for example rice husks, [1], it is very unlikely that gas turbine power plants get phased out. Such plants have a long life that range between twenty to forty years, as well as their operation versatility in adding up to the power supply to meet the peak values of the demand. In addition to, utilization of fossil fuels lead to harmful effects to the environment such as greenhouse gases, thus sustainable

\footnotetext{
* Corresponding author.

E-mail address: motaz.medhat@cu.edu.eg
}

https://doi.org/10.37934/arfmts.87.3.113133 
energy resources should be increasingly utilized to avoid these effects. Ammonia $\left(\mathrm{NH}_{3}\right)$ is considered as carbon-free alternative fuel having a good potential for future power generation and industry. In addition, it is carrying $17.8 \%$ of its weight hydrogen and the products of its complete firing are water vapor and nitrogen only. In comparison, $\mathrm{NH}_{3}$ has some appealing characteristics relative to hydrogen, such as lower cost for storage, higher volumetric density that can be easily transported, stored in liquid phase, experience in manufacturing and handling come from its history in some industries (e.g. chemical industry), and much safer transport due to its lower reactivity when compared to hydrogen [2]. However, utilizing ammonia in various applications faces some challenges concerning high ignition energy required, lower burning velocity compared to hydrocarbon fuels, narrow flammability ranges and high NO emissions generated during its oxidation $[3,4]$. However, the problems of narrow flammability ranges and high ignition energy is discussed in studies that focused on improvement of combustion performance of application that utilize ammonia as fuel such as combustion in spark ignition and compression ignition engines [5-10] founded that mixing ammonia with other fuels such as hydrogen enhance reactivity and increase combustion velocity.

Furthermore, experimental and numerical studies investigated the influence of swirling of entrained ammonia mixture on the flame stability under various conditions [11]. Somarathne et al., $[12,13]$ investigated a LES numerical study for combustion of turbulent premixed ammonia/air flames. The results showed that introducing recirculation zones increases mixing and flame stability of the flame under different turbulent intensities and initial temperatures. Moreover, these studies predicted a reduction of $\mathrm{NO}$ and unbrnt $\mathrm{NH}_{3}$ emissions together at specific rich flame conditions $(\Phi$ of 1.2 and 1.15 ) and high initial temperature.

In addition, Valera-Medina et al., [14] presented a one dimensional experimental study for oxidation of ammonia/methane mixture $\left(0.61 \mathrm{NH}_{3}\right.$ and $\left.0.39 \mathrm{CH}_{4}\right)$ in a swirl stabilized flame at various conditions of pressure (atmospheric and $0.2 \mathrm{MPa}$ ) and equivalence ratios. The study showed that at rich conditions $(\Phi=1.2)$ there is a clear reduction occurred in NO emissions but emissions of unburnt $\mathrm{NH}_{3}$ were not correctly investigated. Also, the influence of increasing pressure over atmospheric pressure indicated a reduction in NO emissions. Furthermore, Kurata et al., $[15,16]$ studied a swirl stabilized non premixed flame of $\mathrm{NH}_{3}$ /air mixture in a $50 \mathrm{~kW}$ gas turbine combustor and the study reported a high NO emissions generated compared with environmental requirement of $70 \mathrm{ppm}$ [17]. Other research groups also published studies of comprehensive analysis about emission created from burning ammonia. The influence of increasing pressure over atmospheric pressure in the reduction of NO emissions is reported in the analysis study of Duynslaegher et al., [18], and Hayakawa et al., [19]. However, increasing the pressure was also shown to play an important role in decreasing the burning velocity in $\mathrm{NH}_{3}$ /air flames [20].

On the other hand, utilizing a detailed chemical kinetic mechanism for ammonia is important to ensure accurate simulation from the combustion model. Chemical mechanisms have been established to model the oxidation of ammonia. Konnov [21] proposed detailed mechanism of ammonia hydrocarbon with 129 species and 1231 steps. Tian et al., [22] presented chemical mechanism for modeling oxidation of premixed ammonia/methane with 84 species and 703 steps. Another mechanism have been studied by Mendiara and Glarborg [23] for oxidation of $\mathrm{NH}_{3} / \mathrm{CH}_{4}$ with 97 species and 779 steps.

Moreover, modifications for ammonia combustion mechanisms are studied by researchers to be available for various burning conditions. Duynslaegher et al., [24] added reactions to $\mathrm{N}_{2} \mathrm{O}$ formation to the mechanism of Konnov. The role of $\mathrm{HCN}$ in formation of $\mathrm{NO}$ in oxidation hydrocarbon and ammonia-hydrocarbon mixture have been studied by Dagaut et al., [25] via mechanism containing 69 species and 462 reactions. Song et al., [26] utilized a modified reaction mechanism of Klippenstein 
et al., [27] to study the oxidation of ammonia at high pressure (30-100 bar) and temperature (450925K) with mechanism containing 34 species and 204 reactions.

Recently researchers introduced chemical mechanisms for the oxidation of ammonia for utilization ammonia in application as a fuel. Okafor et al., [28] presented mixture of ammoniamethane combustion mechanism, with 59 species and 356 steps, to study the laminar flame speed, with aid of the GRI Mech 3.0 mechanism [29] and that of Tian et al., [22]. Otomo et al., [30] updated the mechanism of Song et al., [26], especially in reactions related to $\mathrm{NH}_{2}, \mathrm{HNO}$ and $\mathrm{N}_{2} \mathrm{H}_{2}$ and introduced a mechanism with 59 species and 356 reactions, for ammonia and ammonia/hydrogen oxidation. Recently detailed mechanism of Glarborg et al., [31] with 151 species and 1397 steps, describing $\mathrm{NO}$ formation through $\mathrm{NNH} / \mathrm{N}_{2} \mathrm{O}$, prompt and thermal mechanisms. Unfortunately, superimposing CFD analysis with detailed chemistry mechanisms in simulating of combustion model is more expensive numerical computation. Reduced mechanisms are developed as a compromise to this problem. In the past, Miller et al., [32] introduced a reduced mechanism for $\mathrm{NH}_{3}$ oxidation, with 23 species and 98 reactions. Okafor et al., [33] reduced the detailed mechanism to 130 reactions and 42 species. In addition to, Xiao et al., [34] presented more than reduced mechanisms for oxidation of ammonia/hydrogen and ammonia/methane. The reduction of NO in burning hydrogen in the environment of compression ignition energy was studied by Taib et al., [35].

This present study that investigates a numerical study for a new swirl stabilized combustor for oxidation of ammonia/hydrogen mixture. CFD two dimensional model simulations of a turbulent flame on RANS including a realizable $k-\varepsilon$ turbulent scheme with the aid of reduced chemistry mechanism [36] were performed under various conditions. Partial premixed combustion model with flame-let concept was selected. Validation for the predicted results with experimental data [37] showed a great agreement when compared with the measured experiments. Moreover, the influence of changing various parameters on emission characteristics is also discussed.

\section{Mathematical Model}

The numerical simulation model via ANSYS R19 [38] solves the governing equations in the axisymmetric cylindrical coordinate ( $r$ and $x$ ), which control the motion direction of the flow in time and space. The general form of the conservation equations are presented and solved as follows

\subsection{Governing Equations}

Mass conservation equation (Continuity)

$\frac{\partial \rho}{\partial t}+\frac{\partial}{\partial x i}\left(\rho u_{i}\right)=0$

Momentum conservation equations

$\frac{\partial}{\partial \mathrm{t}}\left(\rho \mathrm{u}_{i}\right)+\frac{\partial}{\partial \mathrm{x}_{j}}\left(\rho \mathrm{u}_{i} \mathrm{u}_{j}\right)=-\frac{\partial \mathrm{P}}{\partial \mathrm{x}_{i}}+\frac{\partial}{\partial \mathrm{x}_{j}}(\overline{\bar{\tau}})-\frac{\partial}{\partial \mathrm{x}_{j}}\left(\rho \overline{\mathrm{u}^{\prime} \iota \mathrm{u}^{\prime} j}\right)$

where, $\frac{\partial \mathrm{P}}{\partial \mathrm{x}_{i}}$ is the pressure gradient, $\overline{\overline{\mathrm{\tau}}}$ is the stress tensor.

The stress tensor is given by 
$\overline{\bar{\tau}}=\mu\left[\left(\frac{\partial \mathrm{u}_{i}}{\partial \mathrm{x} j}+\frac{\partial \mathrm{u}_{j}}{\partial \mathrm{x}_{i}}\right)-\frac{2}{3} \delta_{i j} \frac{\partial \mathrm{u}_{i}}{\partial \mathrm{x}_{j}}\right]$

where $\mu$ is the molecular viscosity and the volume dilation is expressed in the second term on the right hand side.

Energy conservation equation

$\frac{\partial}{\partial \mathrm{t}}(\rho \mathrm{E})+\frac{\partial}{\partial \mathrm{x} i}\left(\mathrm{u}_{i}(\rho \mathrm{E}+\mathrm{p})\right)=\frac{\partial}{\partial \mathrm{x} i}\left(\lambda_{\mathrm{eff}} \frac{\partial \mathrm{T}}{\partial \mathrm{x} i}-\sum_{\mathrm{k}} \mathrm{h}_{\mathrm{k}} \vec{J}_{\mathrm{k}}+\left(\overline{\bar{\tau}}_{\mathrm{eff}} \mathrm{u}_{i}\right)\right)+\mathrm{S}_{\mathrm{h}}$

$E=h_{s}-\frac{p}{\rho}+\frac{v^{2}}{2}$

$\mathrm{h}_{\mathrm{s}}=\sum_{\mathrm{j}} \mathrm{Y}_{\mathrm{j}} \mathrm{h}_{\mathrm{j}}$

$\mathrm{h}_{\mathrm{j}}=\int_{T r e f}^{T} \operatorname{Cpj} d T$

where, $E$ is the total energy, $h_{s}$ is the sensible enthalpy, $\lambda_{\text {eff }}$ is the turbulent thermal conductivity according to the defined turbulence model, $\lambda_{\text {eff }} \nabla \mathrm{T}$ represents energy transfer due to conduction, $\sum_{\mathrm{k}} \mathrm{h}_{\mathrm{k}} \overrightarrow{\mathrm{J}}_{\mathrm{k}}$ represents energy transfer due to species diffusion, ( $\left.\overline{\bar{\tau}}_{\text {eff }} \mathrm{u}_{i}\right)$ describes the energy transfer due to viscous dissipation and $S_{h}$ is the energy source term due to chemical reaction and any other heat source. The source term due to chemical reaction is determined as follows

$S_{h}=-\sum_{j} \frac{h_{j o}}{{M w_{j}}_{j}} R_{j}$

where $h_{j o}$ is the enthalpy of formation of species $j$ and $R_{j}$ is the rate of species production.

\subsection{Turbulence Modeling}

Realizable k- $\varepsilon$ model

$\frac{\partial}{\partial \mathrm{t}}(\rho \mathrm{k})+\frac{\partial}{\partial \mathrm{x}_{\mathrm{j}}}\left(\rho \mathrm{ku}_{\mathrm{j}}\right)=\frac{\partial}{\partial \mathrm{x}_{\mathrm{j}}}\left[\left(\mu+\frac{\mu_{\mathrm{t}}}{\sigma_{\mathrm{k}}}\right) \frac{\partial \mathrm{k}}{\partial \mathrm{x}_{\mathrm{j}}}\right]+\mathrm{G}_{\mathrm{k}}+\mathrm{G}_{\mathrm{b}}-\rho \varepsilon-\mathrm{Y}_{\mathrm{M}}+\mathrm{S}_{\mathrm{k}}$

$\frac{\partial}{\partial \mathrm{t}}(\rho \varepsilon)+\frac{\partial}{\partial \mathrm{x}_{\mathrm{j}}}\left(\rho \varepsilon \mathrm{u}_{\mathrm{j}}\right)=\frac{\partial}{\partial \mathrm{x}_{\mathrm{j}}}\left[\left(\mu+\frac{\mu_{\mathrm{t}}}{\sigma_{\varepsilon}}\right) \frac{\partial \varepsilon}{\partial \mathrm{x}_{\mathrm{j}}}\right]+\rho \mathrm{C}_{1} \mathrm{~S} \varepsilon-\rho \mathrm{C}_{2} \frac{\varepsilon^{2}}{\mathrm{k}+\sqrt{v \varepsilon}}+\mathrm{C}_{1 \varepsilon} \frac{\varepsilon}{\mathrm{k}} \mathrm{C}_{3 \varepsilon} \mathrm{G}_{\mathrm{b}}+\mathrm{S}_{\varepsilon}$

where $C_{1}=\max \left(0.43, \frac{\eta}{\eta+5}\right), \eta=S \frac{k}{\varepsilon}, S=\sqrt{2 S_{i j} S_{i j}}$

The definition of the eddy viscosity is $\mu_{t}=\rho C_{\mu} \frac{k^{2}}{\varepsilon}$ while $C_{\mu}$ is variable and calculated as follows

$$
\mathrm{C}_{\mu}=\frac{1}{\mathrm{~A}_{0}+\mathrm{A}_{\mathrm{s}} \frac{\mathrm{kU}^{*}}{\varepsilon}}
$$


where $U^{*} \equiv \sqrt{S_{i j} S_{i j}+\widetilde{\Omega}_{i j} \widetilde{\Omega}_{i j}}$

And $\widetilde{\Omega}_{\mathrm{ij}}=\Omega_{\mathrm{ij}}-2 \varepsilon_{\mathrm{ijk}} \omega_{\mathrm{k}}$

$\Omega_{\mathrm{ij}}=\overline{\Omega_{\mathrm{lj}}}-\varepsilon_{\mathrm{ijk}} \omega_{\mathrm{k}}$

where $\overline{\Omega_{1 \mathrm{l}}}$ is the mean rate of rotation tensor in a frame rotating with the angular velocity $\omega_{\mathrm{k}}$.

The constants $A_{0}$ and $A_{s}$ are given by

$A_{0}=4.04, A_{s}=\sqrt{6} \cos \emptyset$

where these variables are illustrated in ANSYS R19 [38] as follow

$$
\begin{aligned}
& \emptyset=\frac{1}{3} \cos ^{-1}(\sqrt{6} W), W=\frac{S_{i j} S_{j k} S_{k i}}{\widetilde{S}^{3}}, \\
& \tilde{S}=\sqrt{S_{i j} S_{i j}} S_{i j}=\frac{1}{2}\left(\frac{\partial u_{j}}{\partial x_{i}}+\frac{\partial u_{i}}{\partial x_{j}}\right)
\end{aligned}
$$

\subsection{Combustion Modeling}

Partial premixed model has been selected to predict the flame characteristic due to the reactivity difference between fuel mixtures as reported in the laminar flame speed results shown in Otomo et al., [30]. The probability density function (PDF) model is preferred in simulating the influence of chemical kinetic in turbulent flows with partially premixed combustion model [39]. The following transport conservation equations are considered to integrate chemical reactions of the kinetic mechanism [36] into turbulence calculations. The model solves a transport equation for the mean reaction progress variable, $c$ (to determine the position of the flame front),

$\frac{\partial}{\partial \mathrm{t}}(\rho c)+\nabla \cdot(\rho \overrightarrow{\mathrm{v}} \mathrm{c})=\nabla \cdot\left(\frac{\mu_{\mathrm{t}}}{\mathrm{S}_{\mathrm{ct}}} \nabla \mathrm{c}\right)+\rho \mathrm{S}_{\mathrm{c}}$

where, $c$ is the mean progress variable, $S_{c t}$ is the turbulent Schmidt number, $\vec{v}$ is the velocity vector and $\mathrm{S}_{\mathrm{c}}$ is the source term of reaction progress. Moreover, the model solves a transport equation for the mean mixture fraction, $\bar{f}$ and the mixture fraction variance, $\overline{f^{\prime 2}}$. The Favre mean (densityaveraged) mixture fraction equation is

$\frac{\partial}{\partial \mathrm{t}}(\rho \bar{f})+\nabla \cdot(\rho \overrightarrow{\mathrm{v}} \bar{f})=\nabla \cdot\left(\frac{\mu_{\mathrm{t}}}{\sigma_{\mathrm{t}}} \nabla \bar{f}\right)$

There is no source term in Eq. (11) because that elements are conserved in chemical reactions.

$\frac{\partial}{\partial \mathrm{t}}\left(\rho \overline{f^{\prime 2}}\right)+\nabla \cdot\left(\rho \overrightarrow{\mathrm{v}} \overline{f^{\prime 2}}\right)=\nabla \cdot\left(\frac{\mu_{\mathrm{t}}}{\sigma_{\mathrm{t}}} \nabla \overline{f^{\prime 2}}\right)+\mathrm{C}_{\mathrm{g}} \mu_{\mathrm{t}}(\nabla \vec{f})^{2}-\mathrm{C}_{\mathrm{d}} \rho \frac{\varepsilon}{k} \overline{f^{\prime 2}}+\mathrm{S}_{\mathrm{user}}$

where $f^{\prime}=f-\bar{f}$. The default values for the constants $\sigma_{t}, C_{g}$, and $C_{d}$ are $0.85,2.86$, and 2.0, respectively, and $S_{\text {user }}$ is any user-defined source term. The mean reaction rate in Eq. (10) is modeled as [40] 
$\rho S_{c}=\rho_{u} U_{t}\left|\nabla_{c}\right|$

where $\rho_{\mathrm{u}}$ is the density of is unburnt mixture and $\mathrm{U}_{\mathrm{t}}$ is the turbulent flame speed.

$\mathrm{U}_{\mathrm{t}}=A\left(u^{\prime}\right)^{\frac{3}{4}} \mathrm{~S}^{\frac{1}{2}} \alpha^{\frac{-1}{4}} \mathrm{l}_{t^{\frac{-1}{4}}}$

$\mathrm{U}_{\mathrm{t}}=A u^{\prime}\left(\frac{\tau_{t}}{\tau_{c}}\right)^{\frac{1}{2}} \alpha^{\frac{-1}{4}} \mathrm{l}_{t}^{\frac{-1}{4}}$

A is the model constant, the default value given by Zimont [41] is 0.52 and was later reduced to 0.38 following Yehia \& Abdel-Raheem [42], $u^{\prime}$ is the root mean square velocity, $S_{l}$ is the laminar flame speed, $I_{t}$ is turbulence length scale, $\tau_{t}=l_{t} / u^{\prime}$ is the turbulent time scale and $\tau_{c}=\alpha / S_{l}{ }^{2}$ is the chemical time scale.

\subsection{Scalar Quantities}

Fraction of species and temperature or any other mean scalar is denoted by $\bar{\emptyset}$, are determined via probability density function (PDF) of $f$ and $c$ as

$\bar{\emptyset}=\int_{0}^{1} \int_{0}^{1} \varnothing(f, c) p(f, c) d f d c$

The probability density function model of $\beta$-PDFshape, for the mixture fraction $(f)$ given by

$p(f)=\frac{f^{\alpha-1}(1-f)^{\beta-1}}{\int f^{\alpha-1}(1-f)^{\beta-1} \mathrm{~d} f}$

where

$\alpha=\bar{f}\left[\frac{\bar{f}(1-\bar{f})}{f^{\prime 2}}-1\right]$

And

$\beta=(1-\overline{\mathrm{f}})\left[\frac{\overline{\mathrm{f}}(1-\overline{\mathrm{f}})}{\overline{\mathrm{f}^{\prime 2}}}-1\right]$

\subsection{Kinetic Mechanism}

The reduced Okafor's mechanism [36] which reduced from Okafor's mechanism [33] for the oxidation of $\mathrm{NH}_{3} / \mathrm{H}_{2}$ is selected due to its lower computational cost achieved via using lower number of species in chemistry calculations. The kinetic mechanism containing 19 species and 63 reactions was validated by the author [33] against Okafor's mechanism [36] and experimental data from others [20,43-46] for laminar flame speed calculated. The reduced mechanism [36] is described in supplementary material.

Diagram in Figure 1 presented a formation of $\mathrm{NO}$ during oxidation of $\mathrm{NH}_{3} / \mathrm{H}_{2}$ mixture reaction at stoichiometric condition [36]. Paths showed that the major role of oxidation $\mathrm{HNO}, \mathrm{NH}, \mathrm{NH}_{2}$ and $\mathrm{N}$ in production of NO. Thickness of the paths illustrates the high and low contribution in production of $\mathrm{NO}$ during oxidation of $\mathrm{NH}_{3} / \mathrm{H}_{2}$ flame. Ammonia is initially produced $\mathrm{NH}_{2}$ when it consumed with $\mathrm{O}$ 
and $\mathrm{OH}$ and then $\mathrm{NH}_{2}$ presented $\mathrm{NH}$ and $\mathrm{HNO}$ when it reacted with $\mathrm{OH}, \mathrm{H}$ and $\mathrm{H}$. The major amount contribution in production of $\mathrm{NO}$ is considered to come from the reactions of $\mathrm{HNO}$ with $\mathrm{OH}, \mathrm{O}_{2}$ and $\mathrm{H}$. The reactions of $\mathrm{NH}$ with $\mathrm{O} / \mathrm{O}_{2}$ and $\mathrm{N}$ with $\mathrm{OH} / \mathrm{O}_{2}$ converted to $\mathrm{NO}$ but with lower contribution when compared to HNO.

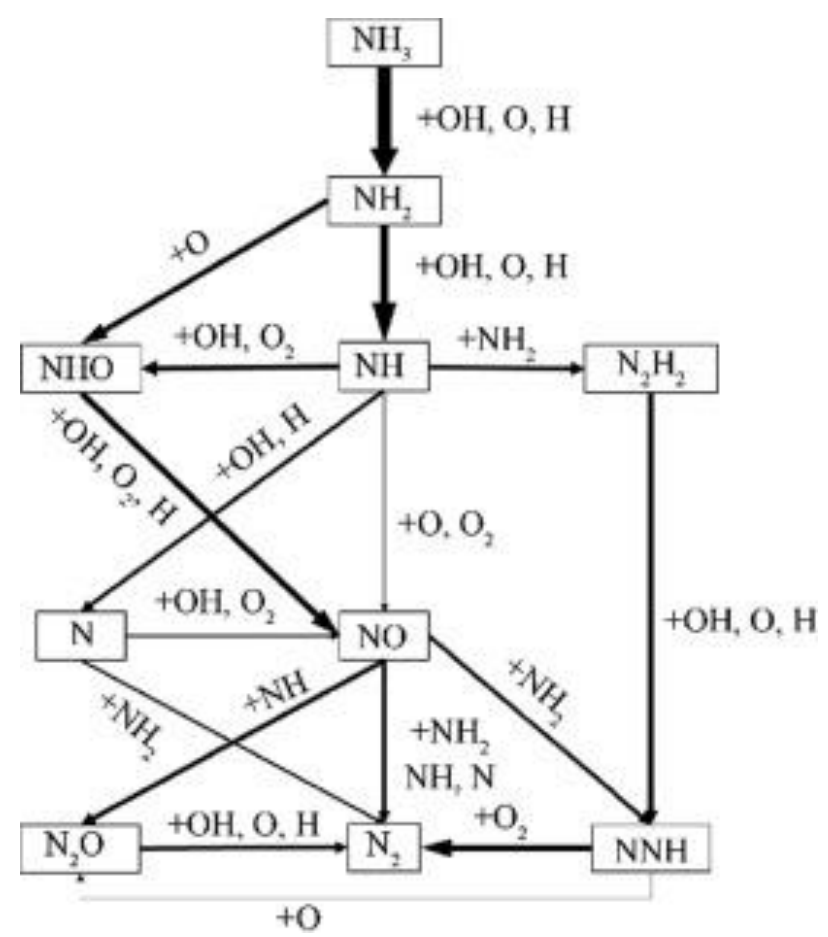

Fig. 1. Path analysis describing the oxidation of $\mathrm{NH}_{3} / \mathrm{H}_{2}$ flame [36]

The kinetic mechanism [36] is imported into the partially premixed combustion model to simulate oxidation of ammonia/hydrogen mixture exactly. The modeling of chemical reaction in the chemistry mechanism is generated via PDF (Probability Density Function) model. The laminar flame speed have a major role in simulating the model precisely, but the laminar flame speed data available in ANSYS FLUENT [38] is obtained from other research studies for hydrogen, methane, acetylene, ethylene, ethane and propane fuels in various conditions of pressures, temperatures and equivalence ratios [47]. In addition to, the laminar flame speed changes with the change of chemical composition and equivalence ratio. For these reasons, accurate laminar flame speed needs to be calculated from one dimensional prediction study or from experimental measurements. Thus, the data of laminar flame speed variations with equivalence ratio are taken from Otomo et al., [30], due to its account for the various conditions in the present study (Figure 2). 


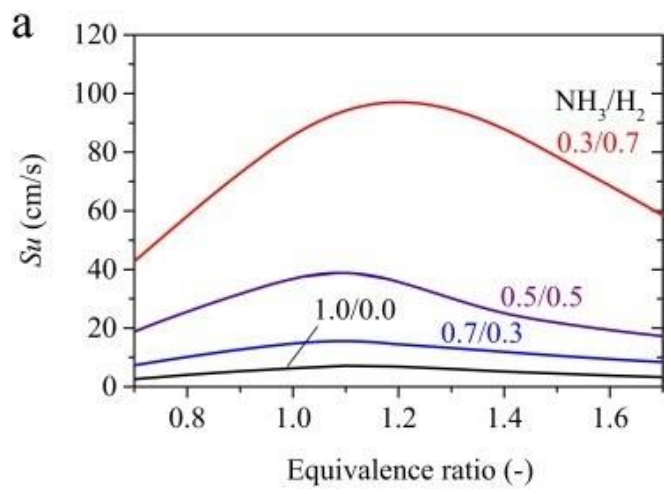

(a)

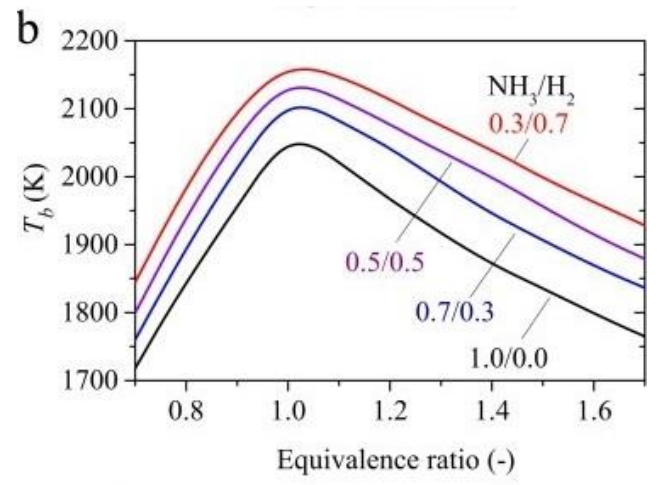

(b)

Fig. 2. (a) burning velocity, Su and (b) adiabatic flame temperature, $\mathrm{Tb}$ in $\mathrm{NH}_{3} / \mathrm{H}_{2} /$ air mixtures [30]

\section{Problem Description}

The combustor is vertically fired (as shown in Figure 3) with $100 \mathrm{~mm}$ diameter and $320 \mathrm{~mm}$ height. Initially, air is introduced tangentially inside the premixing tube of $400 \mathrm{~mm}$ length, while fuel mixture is issued radially from 12 holes of $2 \mathrm{~mm}$ diameter. To attain improved mixing and flame stability, the burner combines air swirl with a bluff body. The $1.9 \mathrm{~kW}$ capacity burner shown in Figure 1 utilized in the present study is a swirl-stabilized ammonia/hydrogen mixture used in the study of Costa, et al., [37].

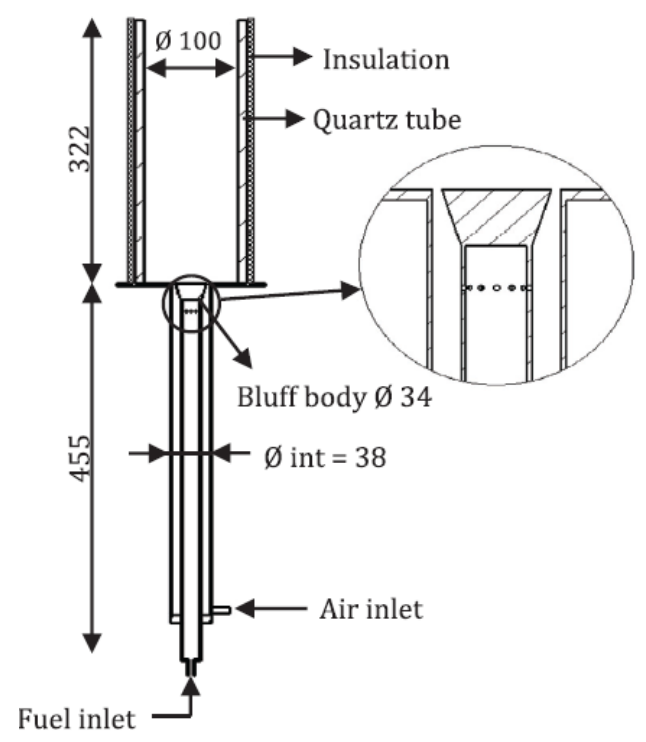

Fig. 3. Combustor geometry [37]

Figure 4 shows 2D axisymmetric geometry for combustion chamber. A axisymmetric for the combustor has been taken for the present study to minimize the simulation time.

The utilizing meshing consists of $3.5 \times 10^{5}$ triangle elements as shown in Figure 3 , with quality of (1.56 in average) aspect ratio for total elements. Near burner tip and outlet the mesh required to be condensed due to the importance of the flame in these regions as shown in Figure 5. Figure 6 shows the grid independence study for get agreement for utilizing mesh grid.

The predicted radial temperature at different locations in combustion chamber for case of $80 \%$ $\mathrm{NH}_{3}$ with 0.8 equivalence ratio is compared for different mesh grid sizes of $2.5 \times 10^{5}$ cells, $3.5 \times 10^{5}$ cells and $6.5 \times 10^{5}$ cells. The grid size of $2.5 \times 10^{5}$ cells shows a deviation in predicted radial temperature in 
comparison with the grid size of $3.5 \times 10^{5}$ cells and $6.5 \times 10^{5}$ cells which gives results almost identical. Thus, choosing grid size of $3.5 \times 10^{5}$ cells are deemed to be suitable for this study.

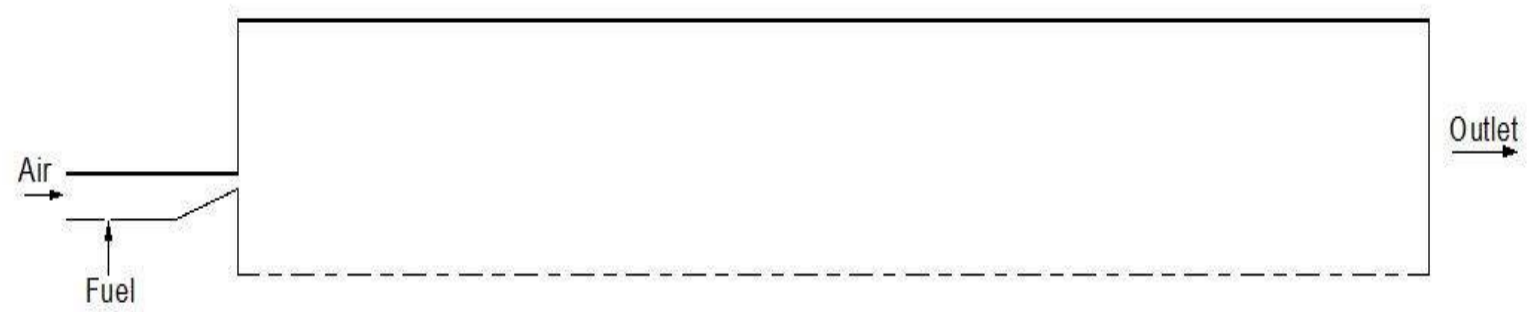

Fig. 4. 2D axisymmetric geometry for combustion chamber

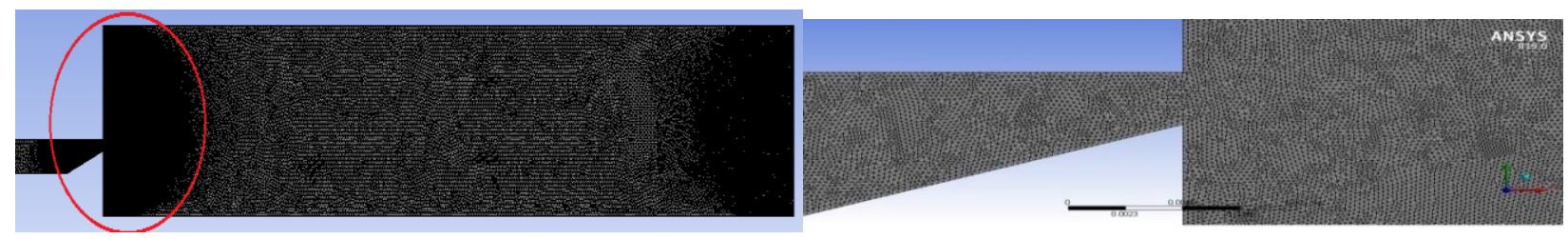

Fig. 5. 2-D geometry mesh

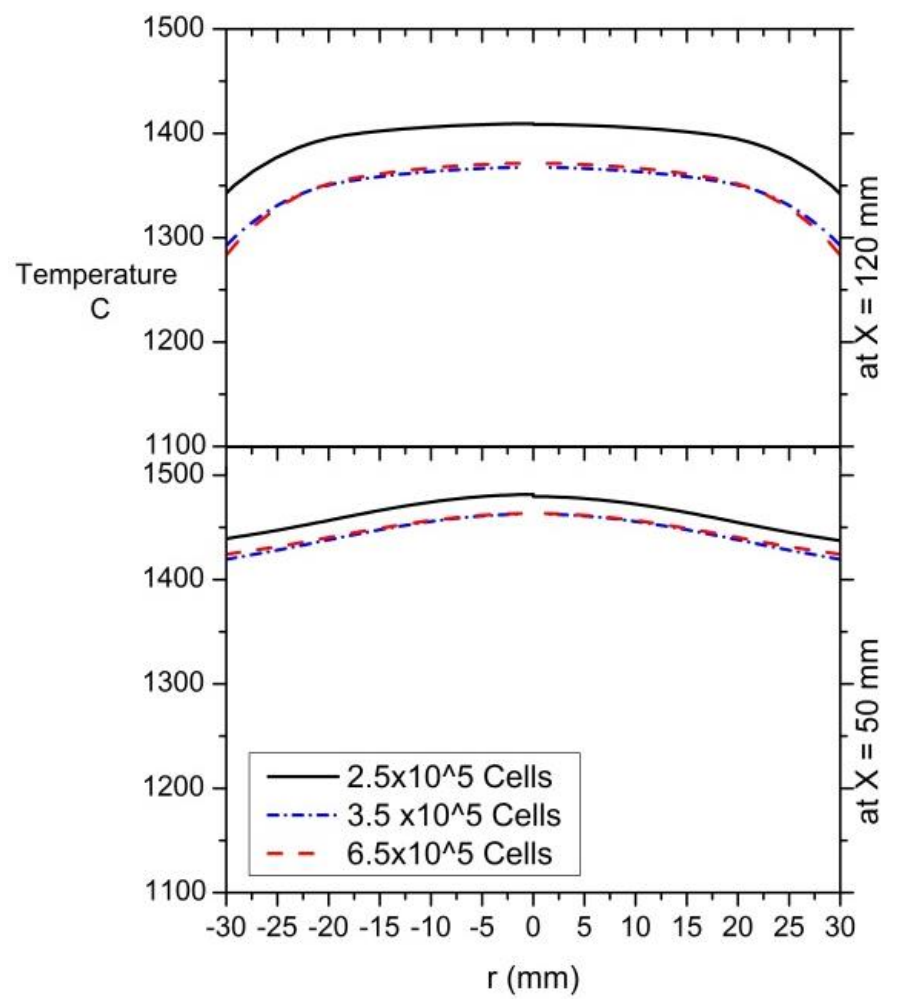

Fig. 6. Radial temperature comparison for various mesh sizes at different locations in the combustor

\section{Cases Studied and Boundary Conditions}

The 2- $d$ model of combustion is partially premixed model with steady non adiabatic flame-let mixture and the radiation model is do. Simulations of a turbulent flame in the present study rely on Realizable $k-\varepsilon$ turbulent scheme due to its ability to deal with swirling flow when compared with other $k-\varepsilon$ models and to minimize time cost [48]. 
Discretization for flow conservation equations is utilized 2 nd order upwind scheme and for pressure and velocity coupling the Coupled algorithm is selected. In order to attain accuracy in the predicted results the solution convergence criteria is controlled via monitoring the residual of continuity, momentum, and energy are less than $10^{-3}, 10^{-5}$ and $10^{-6}$, respectively.

The air and fuel enter at $300 \mathrm{~K}$ and the walls have convection boundary condition with $10 \mathrm{~W} / \mathrm{m}^{2} \mathrm{~K}$ heat transfer coefficient and the stream of air at $300 \mathrm{~K}$ except for walls of chambers not the bottom of chamber kept to be coupled boundary condition.

\section{Results}

The predicted results are firstly validated with experimental data [37] for cases of different concentration of $\mathrm{NH}_{3}$ and at equivalence ratio as shown in Table 1.

Table 1

Conditions of validated cases

\begin{tabular}{llll}
\hline Cases & Concentration of $\mathrm{NH}_{3}$ & $\Phi$ & $\mathrm{P}(\mathrm{Mpa})$ \\
\hline Flame 1 & $70 \% \mathrm{NH}_{3}$ & 0.8 & 0.1 \\
Flame 2 & $80 \% \mathrm{NH}_{3}$ & 0.8 & 0.1 \\
Flame 3 & $90 \% \mathrm{NH}_{3}$ & 0.7 & 0.1 \\
Flame 4 & $90 \% \mathrm{NH}_{3}$ & 0.8 & 0.1 \\
Flame 5 & $90 \% \mathrm{NH}_{3}$ & 0.9 & 0.1 \\
\hline
\end{tabular}

The dry volumetric emissions of $\mathrm{O}_{2}$ and $\mathrm{NO}_{x}$ are validated with the experimental data [37] as shown in Figure 5 and 6 respectively.The axial temperature is validated with the experimental data [37] that shown in Figure 8 to present agreement with experimental one (Figure 7) [37] except in the location of entrained mixture from the annuals due to the increasing of mixing at this locations. Enhancement of the mixture mixing and the stability of the flame in the burner is due to the effect of tangentially entrained air and the introduced bluff body that leads to generation of internal recirculation zone at the combustor region where the temperature increases and then the dilution occurred and the temperature then decreased till to reach outer recirculation zone.

The axial temperature distribution along the axis of the combustor illustrates the increase in the temperature near the bottom of the burner. Therefore, the increase in temperature near the bottom of the burner is due to the influence of recirculation zone in increasing mixing and also indicates that hydrogen concentration is utilized near the bottom of the burner. 


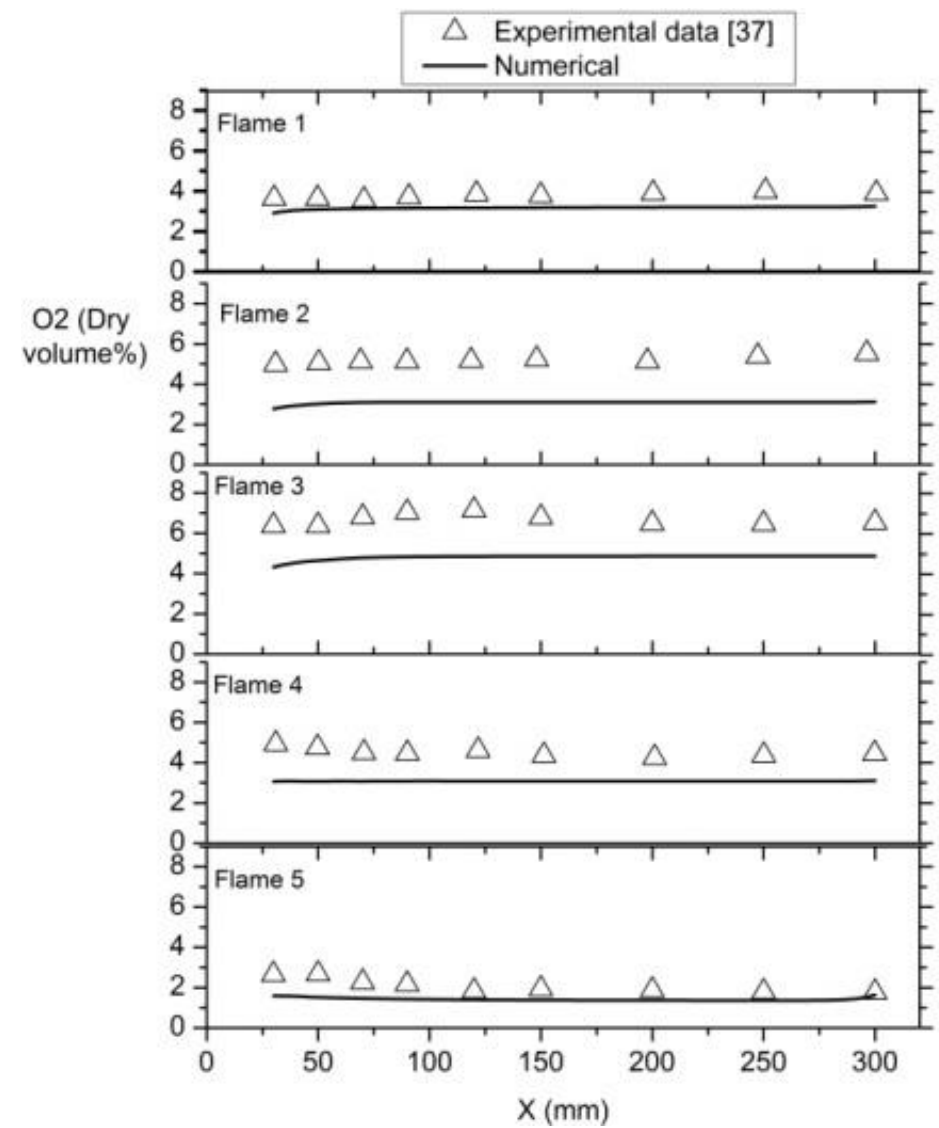

Fig. 7. Comparison of the experimental data [37] and calculated $\mathrm{O}_{2}$ at the center of the combustion chamber

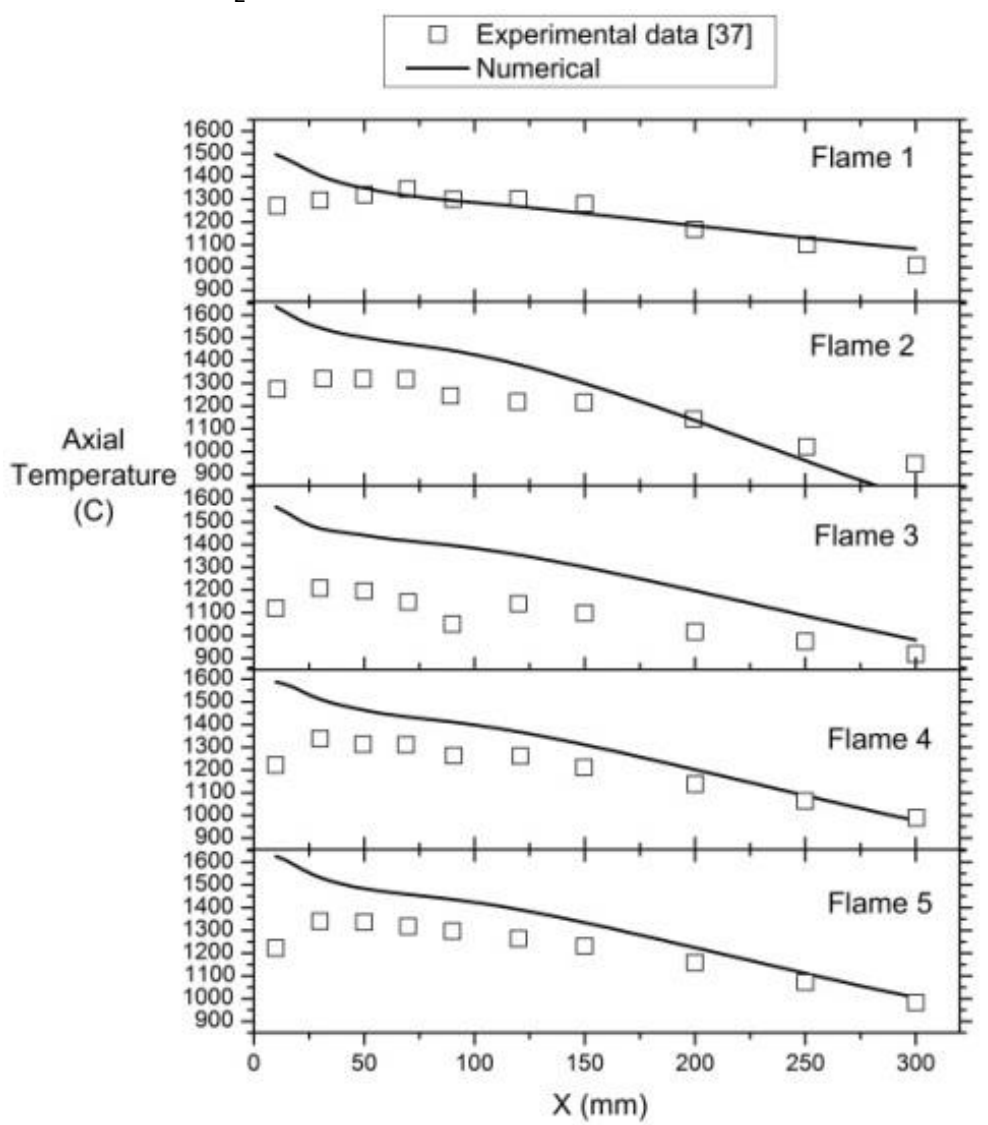

Fig. 8. Comparison of the experimental and calculated axial temperature at the center of the combustor [37] 


\subsection{Flame Stability}

In order to examine the influence of swirling flow that introduced via bluff body burner design and the stability of ammonia/hydrogen flame in the burner, study of flow field and combustion characteristics via numerical simulations are adopted. The flow field formed from the burner is presented in Figure 9. The flow field pattern introduces two recirculation zones, the primary one is inner recirculation zone (IRZ) that is mainly related to the introduced swirling flow and bluff- body design, whereas smaller external recirculating zone (ERZ) between the high velocity zone and the bounding walls, generated by the rapid expansion of the swirling flow from annuals into the burner $[49,50]$. As a result of generation of the IRZ in the burner, the stability of the mixture is achieved by the enhancement of the mixture mixing via carrying the radicals, unburnt and burnt gases into combustion chamber. The reduction in the average velocity developed in the IRZ lead to increasing the time of chemical reaction resulting in relatively higher reaction rates.

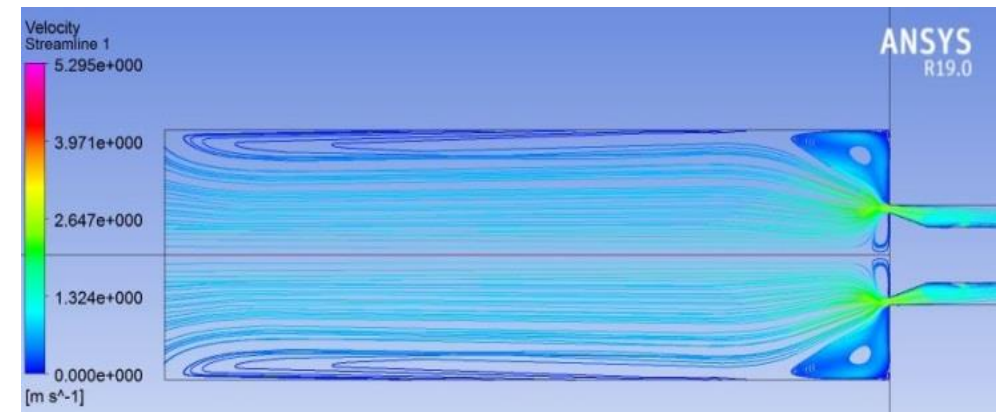

Fig. 9. Velocity streamline for case of $70 \% \mathrm{NH}_{3}$ at $\Phi=0.8$

\subsubsection{Flame characteristics at lean condition}

Moreover, the present study investigated the influence of mixing ammonia with different compositions of hydrogen at lean condition $(\Phi=0.5)$ as shown in Figure $10(a, b$ and $c)$. Higher temperature near the burner tip and longer flame length is considered for high hydrogen concentration in the mixture due to high reactivity and burning velocity of hydrogen. However, temperature contours in Figure 10 ( $d$ and e) show that the reduction of hydrogen composition in the mixture leads to blow off of the flame into the chamber.

On the other hand, higher activity of hydrogen as compared to pure ammonia oxidation flames leads to flash back occurring into the chamber as shown in Figure 12 ( $a, b$ and $c$ ). Contours of temperature illustrate that in cases of high hydrogen concentration in the mixture, the increase in equivalence ratio towards to rich condition leads to the flash back into the chamber. While, Figure 12 ( $d$ and e) show that the reduction in hydrogen composition in the mixture at increasing of equivalence ratio will not lead to blow off condition to the flame as in cases of equivalence ratio is lower than 0.8 . 


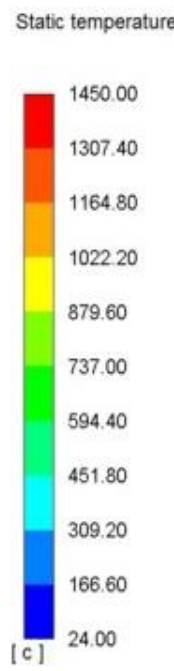

(a)

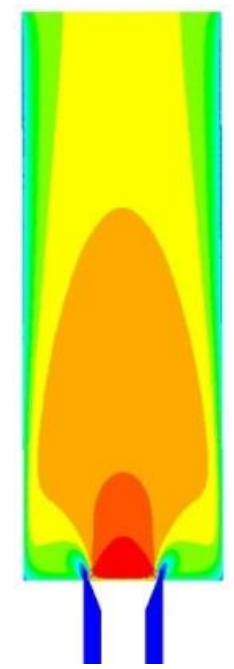

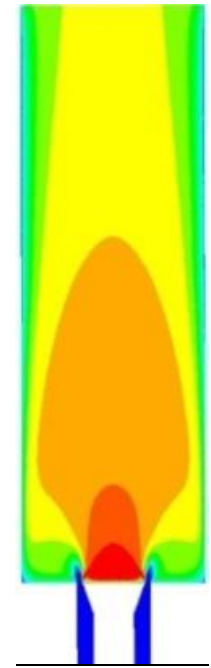

(b)

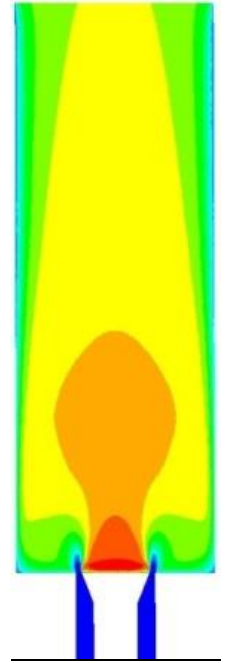

(c)

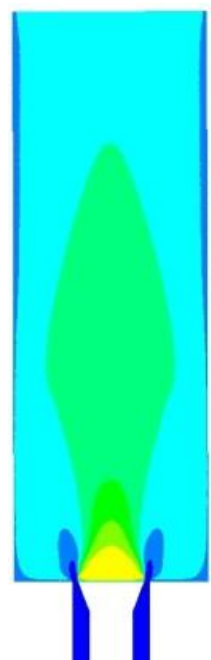

(d)

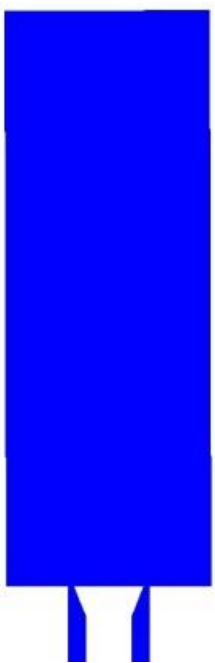

(e)

Fig. 10. Temperature contours for different fuel composition ( $a=50 \%, b=40 \% c=20 \%, d=10 \%$ and $e=0 \% \mathrm{H}_{2}$ ) at $\Phi=0.5$

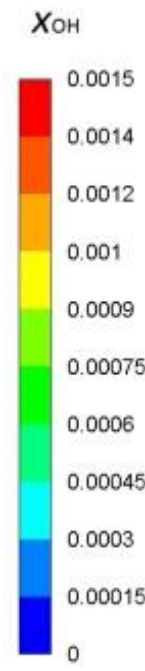

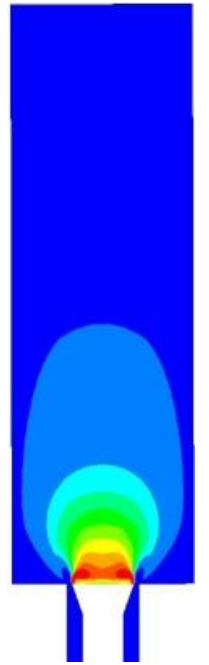

(a)

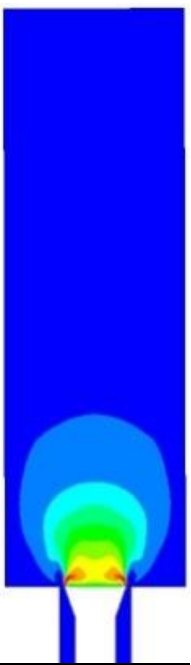

(b)

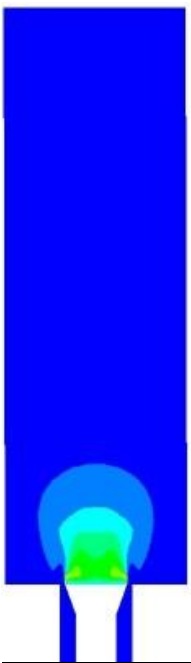

(c)

Fig. 11. Mole fraction of $\mathrm{OH}$ contours for different fuel composition $\left(a=50 \%, b=40 \%\right.$ and $\left.c=20 \% \mathrm{H}_{2}\right) \Phi=0.5$ 


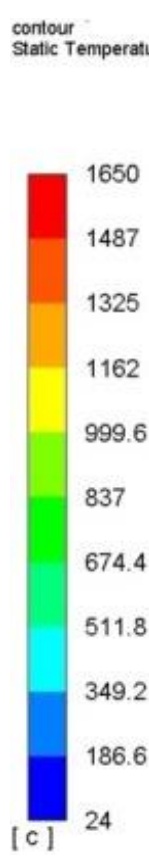

(a)

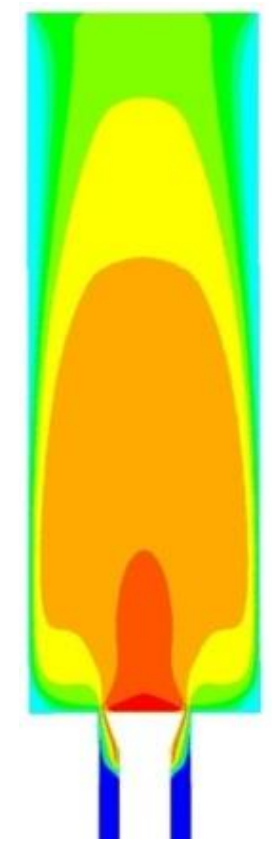

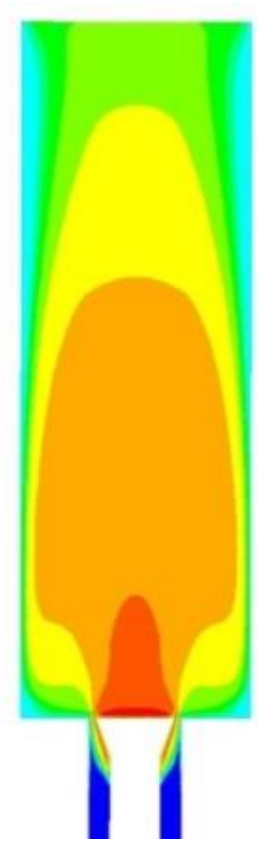

(b)

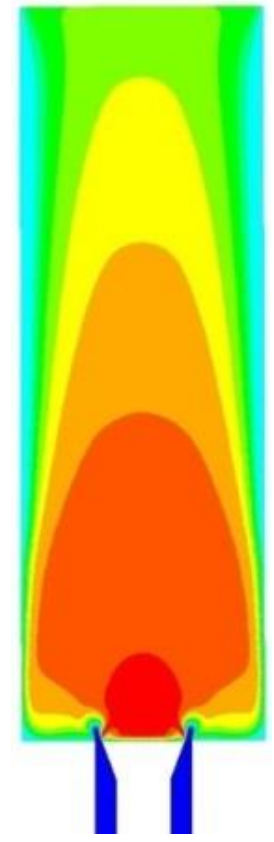

(c)

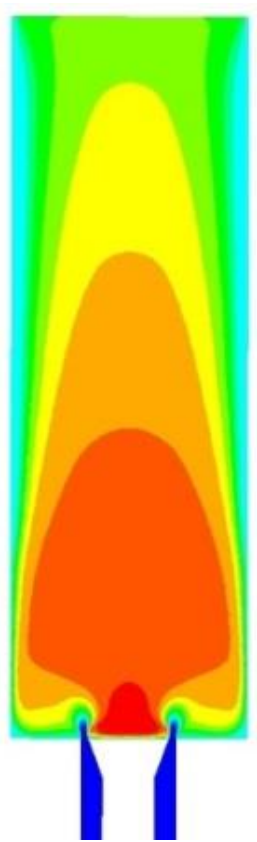

(d)

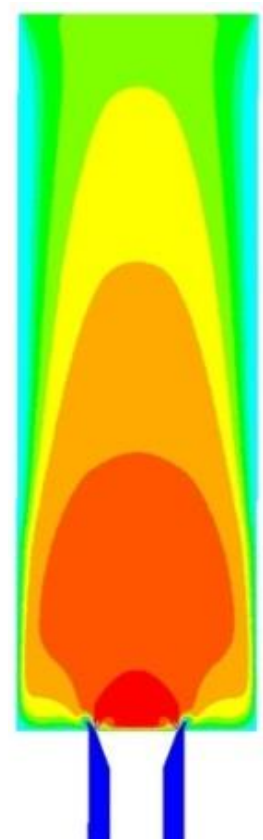

(e)

Fig. 12. Temperature contour for cases of $\left(a=50 \%, b=40 \% c=20 \%, d=10 \%\right.$ and $\left.e=0 \% \mathrm{H}_{2}\right)$ at $\Phi=0.8$

\subsubsection{Flame characteristics at stoichiometric}

The flame characteristics of $\mathrm{NH}_{3} / \mathrm{H}_{2}$ mixture under the stoichiometric condition and initial mixture temperature of $300 \mathrm{~K}$ are shown in the Figure $13(\mathrm{a}, \mathrm{b})$ in terms of temperature contour and mole fraction of $\mathrm{OH}$ respectively. $\mathrm{OH}$ distribution in the chamber illustrates an increase in $\mathrm{OH}$ followed by an increase in the temperature. The important influence of changes of $\mathrm{OH}$ concentration on emissions $\mathrm{NO}$ and unburnt $\mathrm{NH}_{3}$ will be illustrated in the next section.

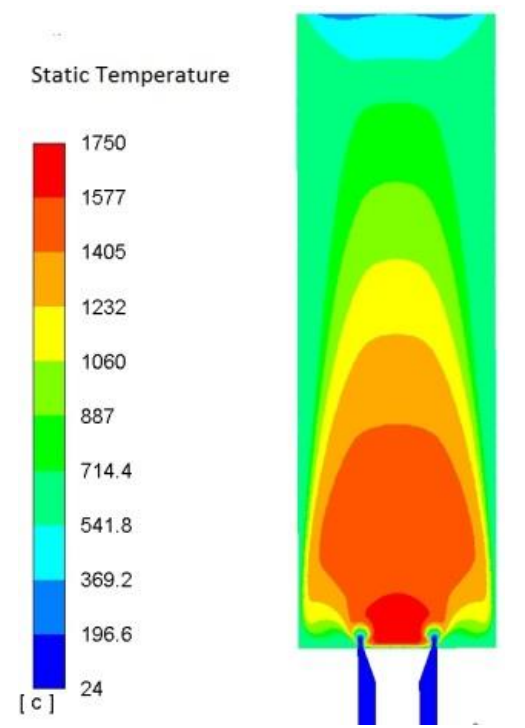

(a)

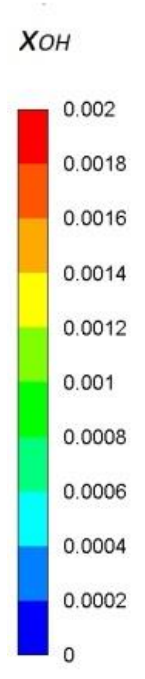

(b)

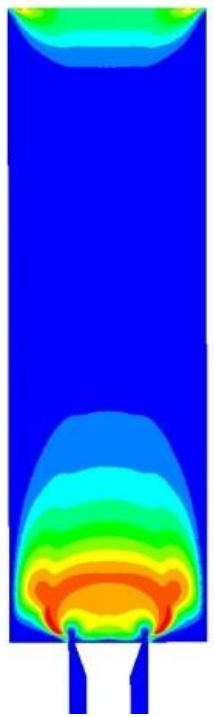

Fig. 13. flame characteristics at $70 \% \mathrm{NH}_{3}$ and stoichiometric condition: (a) Temperature contour; (b) mole fraction of $\mathrm{OH}$ 


\subsubsection{Flame characteristics at rich condition}

The flame characteristics of $\mathrm{NH}_{3} / \mathrm{H}_{2}$ mixture under the rich condition of equivalence ratio equal to 1.2 with initial mixture temperature of $300 \mathrm{~K}$ are shown in the Figure $14(\mathrm{a}, \mathrm{b})$ in terms of temperature contour and mole fraction of $\mathrm{OH}$ respectively. $\mathrm{OH}$ distribution in the chamber illustrates a reduction in $\mathrm{OH}$ concentration as compared with the stoichiometric condition and its effects on decrease of temperature and flame length is shown in Figure 14 (a).

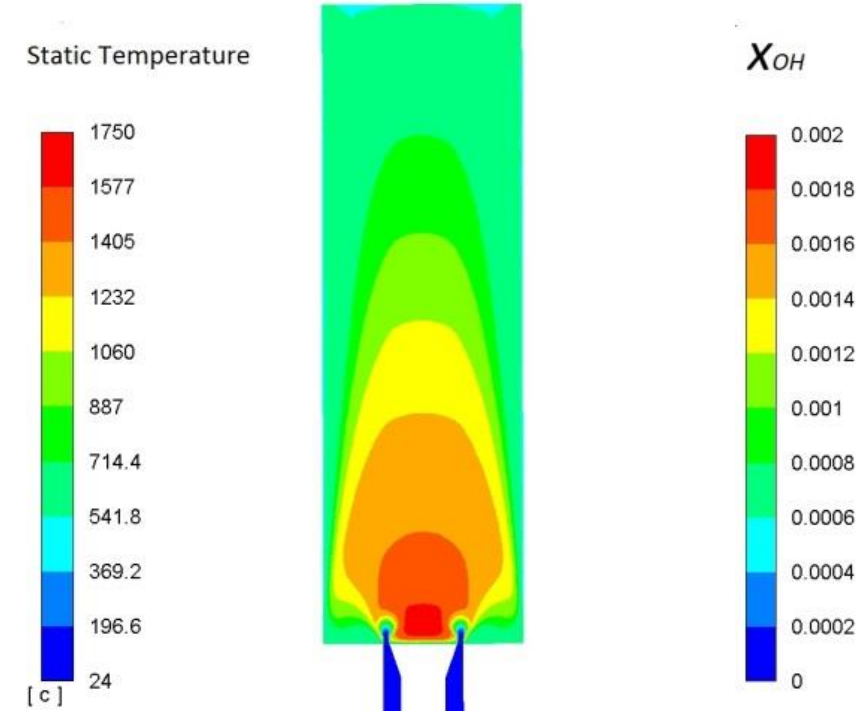

(a) (b)

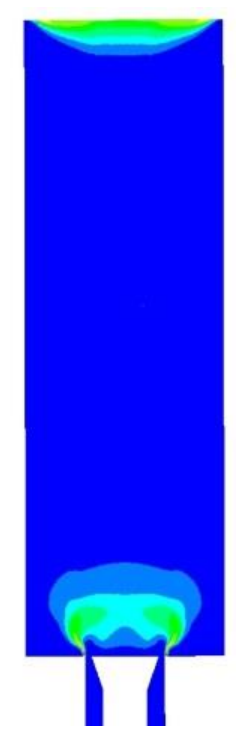

Fig. 14. Flame characteristics at $70 \% \mathrm{NH}_{3}$ at rich condition: (a) Temperature contour; (b) mole fraction of $\mathrm{OH}$

The effect of increasing hydrogen concentration in the mixture on the NO emission is shown in Figure 15. At constant equivalence ratio the increasing in hydrogen content lead to increase of NOx emission.

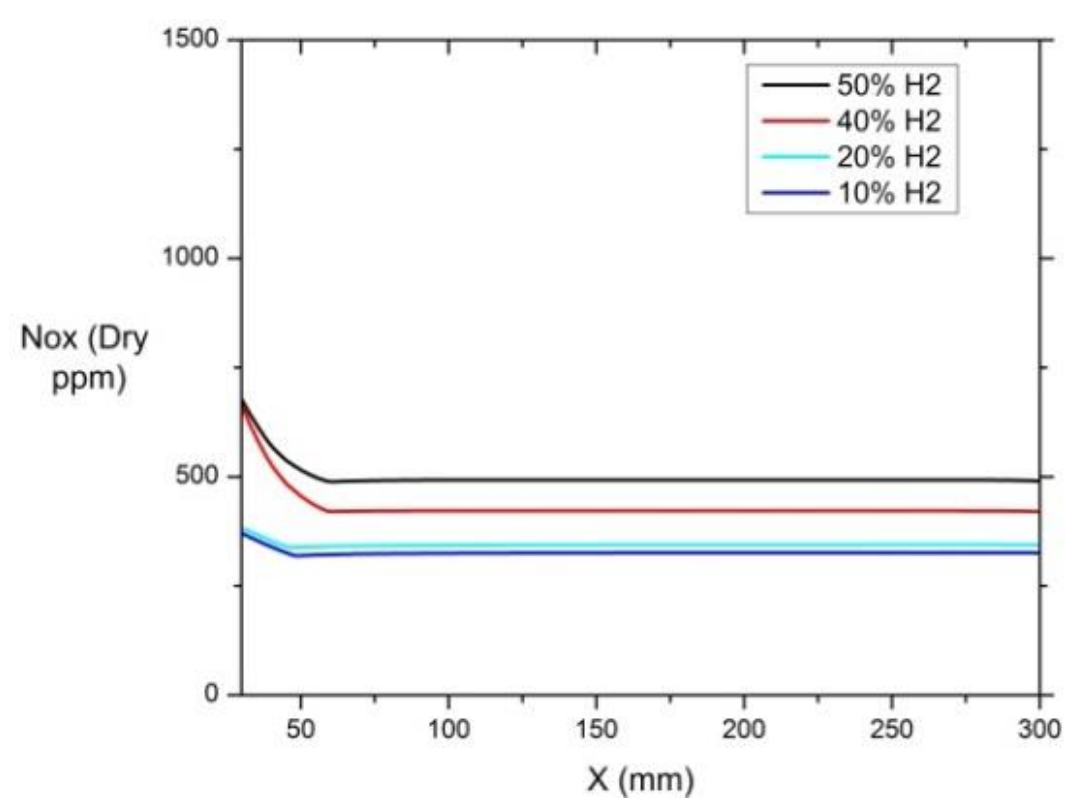

Fig. 15. NOx formation at different hydrogen composition at $70 \% \mathrm{NH}_{3}$ and $\Phi=0.8$ 


\subsection{Effect of Equivalence Ratio}

The emission characteristics for oxidation of $\mathrm{NH}_{3} / \mathrm{H}_{2}$ from lean to rich condition is analyzed at inlet mixture temperature of $300 \mathrm{~K}$ and atmospheric pressure for $70 \% \mathrm{NH}_{3}$ case to show the effect of changing equivalence ratio. Figure 16 ( $a, b, c$ and d) and Figure 17 Show the mole fraction of unburnt $\mathrm{NH}_{3}$ and $\mathrm{NO}_{x}$ formation respectively.

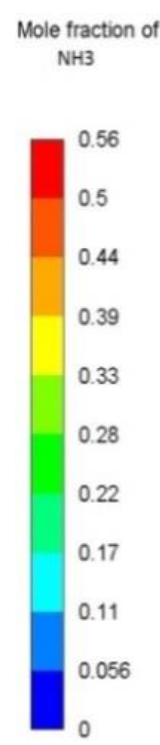

Fig.

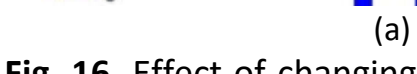

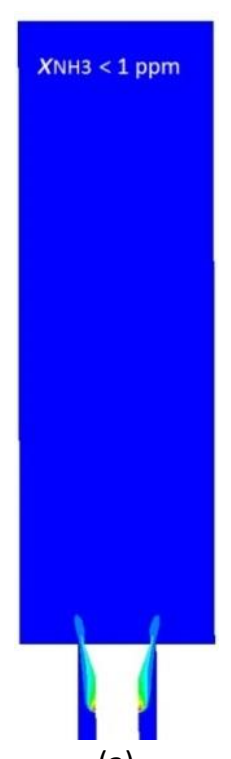

(a)

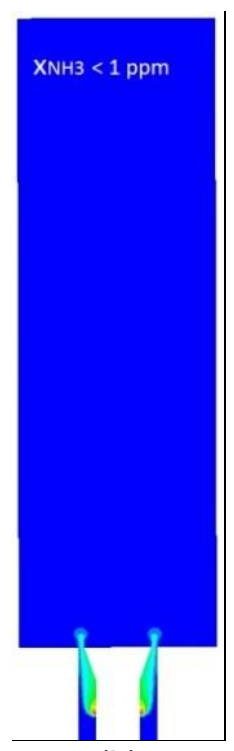

(b)

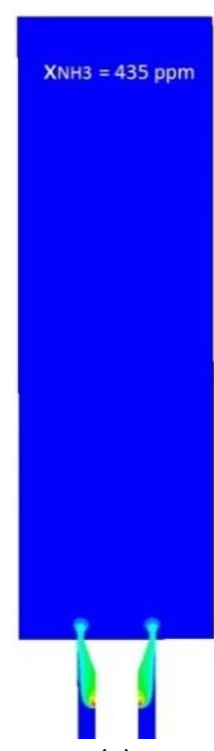

(c)

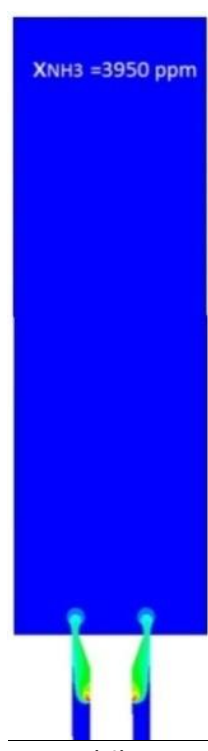

(d)

g. 16. Effect of changing $\Phi$ on mole fraction of $\mathrm{NH}_{3}$ emission at atmospheric pressure for $70 \% \mathrm{NH}_{3}$ at various equivalence ratio $(a=0.5, b=0.8, c=1$ and $d=1.2$ )

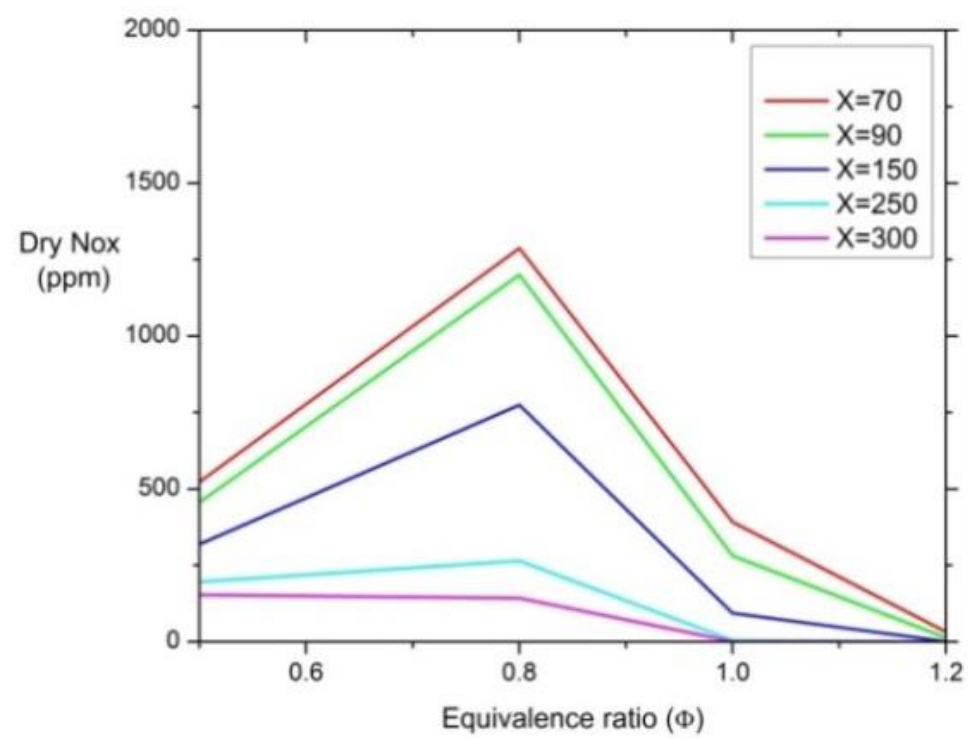

Fig. 17. Effect of changing $\Phi$ on NOx formation at atmospheric pressure and $70 \% \mathrm{NH}_{3}$ predicted at different location in the combustor

The unburnt $\mathrm{NH}_{3}$ increases with respect to equivalence ratio from lean to rich conditions. At rich condition the amount of unburnt $\mathrm{NH}_{3}$ show a significant increase, thus equivalence ratio lower than 1.2 will be preferable to reduce the amount of unburnt $\mathrm{NH}_{3}$ formation. However, the $\mathrm{NO}$ emission characteristic increase with the increase of equivalence ratio to its maximum value around $\Phi=0.8$ till 
reaches the rich condition and then start to decrease. $\mathrm{OH}$ radicals have a major role in the destruction of $\mathrm{NO}$ formation. $\mathrm{OH}$ concentration illustrated in previous section reported that the reduction in $\mathrm{OH}$ radicals faced with decrease in $\mathrm{NO}$ emission. The rich conditions have an important influence in the reduction of $\mathrm{NO}$ and unburnt $\mathrm{NH}_{3}$ emissions but the correct value of the equivalence ratio at rich condition have to be selected to achieve the reduction in both of unburnt $\mathrm{NH}_{3}$ and $\mathrm{NO}$ emissions.

\subsection{Effect of Pressure}

Figure 18 and 19 shows that the increasing of operating mixture pressure over the atmospheric pressure to $0.5 \mathrm{MPa}$ have a significant effect in the reduction of emission concentrations of unburnt $\mathrm{NH}_{3}$ and $\mathrm{NO}$. The reduction of $\mathrm{OH}$ radicals have important role in the reduction of $\mathrm{NO}$ formation and unburnt NH3 [19].

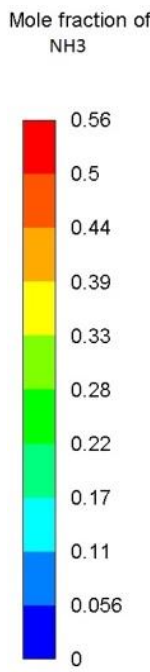

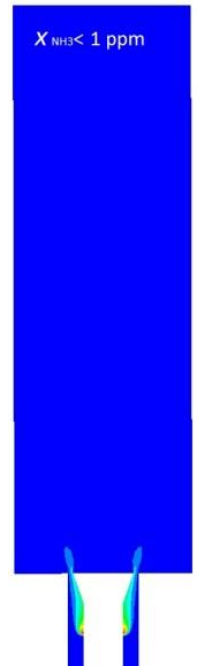

(a)

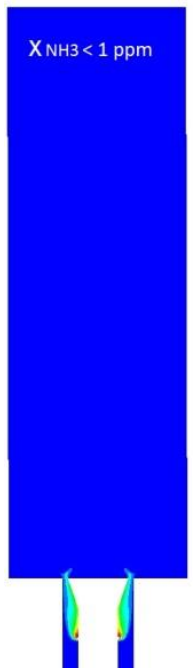

(b)

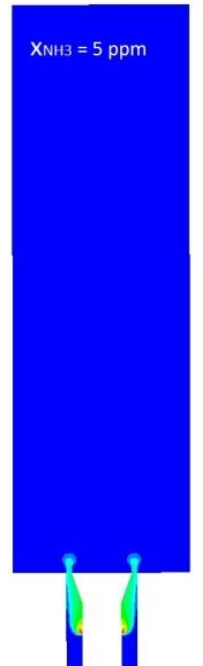

(c)

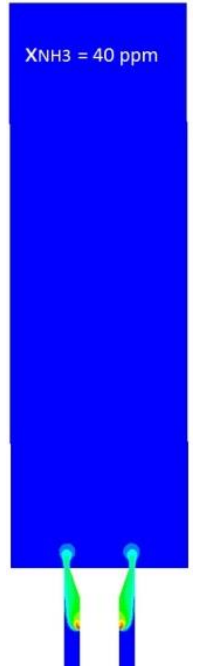

(d)

Fig. 18. Effect of changing $\Phi$ on mole fraction of $\mathrm{NH}_{3}$ at $\mathrm{P}=0.5 \mathrm{MPa}$ and $70 \% \mathrm{NH}_{3}$ at various equivalence ratio $(a=0.5, b=0.8, c=1$ and $d=1.2)$

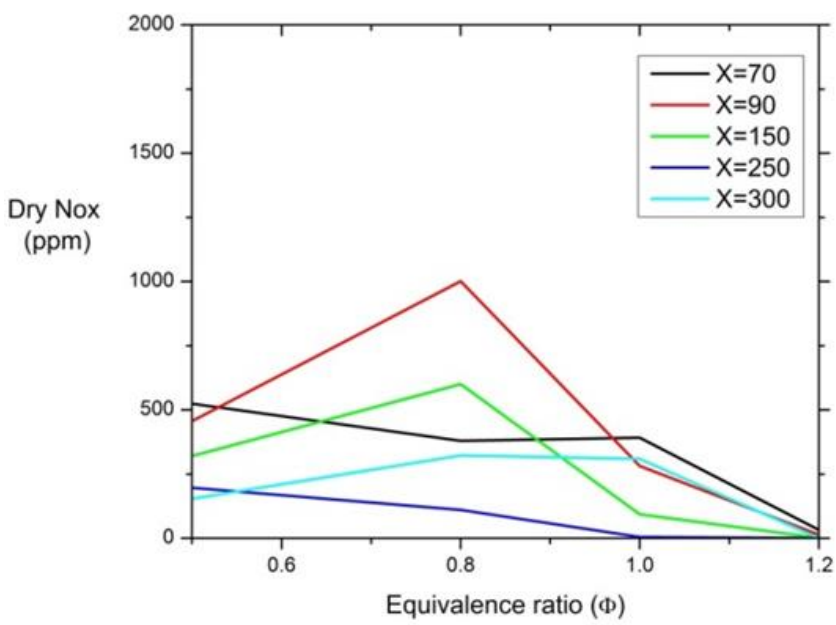

Fig. 19. Effect of changing $\Phi$ on mole fraction of NO at $\mathrm{P}=0.5 \mathrm{MPa}$ and $70 \% \mathrm{NH}_{3}$ predicted at different location in the combustor 


\section{Conclusion}

The computational investigation of burning ammonia hydrogen mixtures in a gas turbine like combustor resulted in the following conclusions

i. As a result of generation of the IRZ in the burner, the stability of the mixture is achieved by the enhancement of the mixture mixing via carrying the radicals, unburnt and burnt gases into combustion chamber

ii. High hydrogen concentration in the mixture at slightly lean condition leads to the flash back into the chamber

iii. At lean condition lower than 0.8 equivalence ratio the reduction of hydrogen composition in the mixture leads to blow off of the flame into the chamber

iv. The rich conditions have an important influence in the reduction of $\mathrm{NO}$ and unburnt $\mathrm{NH}_{3}$ emissions but the correct value of the equivalence ratio at rich condition have to be selected to achieve the reduction in the unburnt $\mathrm{NH}_{3}$ and $\mathrm{NO}$ emissions

v. Equivalence ratio lower than 1.2 will be preferable to reduce the amount of unburnt $\mathrm{NH}_{3}$ formation

vi. The reduction in $\mathrm{OH}$ radicals faced with decrease in $\mathrm{NO}$ emission

vii. The increasing of operating mixture pressure to $0.5 \mathrm{MPa}$ have an significant effect in the reduction of emission concentrations of unburnt $\mathrm{NH}_{3}$ and $\mathrm{NO}$

viii. For constant condition such as constant $\Phi=0.8$ increasing hydrogen content resulted in increasing NOx emissions

ix. For constant ammonia/hydrogen concentrations, NO emissions increases with equivalence ratio then reduced at rich conditions and $\mathrm{NH}_{3}$ emissions are generally low

\section{References}

[1] Lubis, Hamzah. "Renewable Energy of Rice Husk for Reducing Fossil Energy in Indonesia." Journal of Advanced Research in Applied Sciences and Engineering Technology 11, no. 1 (2018): 17-22.

[2] Zamfirescu, C., and I. Dincer. "Using ammonia as a sustainable fuel." Journal of Power Sources 185, no. 1 (2008): 459-465. https://doi.org/10.1016/i.jpowsour.2008.02.097

[3] Nozari, Hadi, and Arif Karabeyoğlu. "Numerical study of combustion characteristics of ammonia as a renewable fuel and establishment of reduced reaction mechanisms." Fuel 159 (2015): 223-233. https://doi.org/10.1016/i.fuel.2015.06.075

[4] Miller, James A., and Craig T. Bowman. "Mechanism and modeling of nitrogen chemistry in combustion." Progress in energy and combustion science 15, no. 4 (1989): 287-338. https://doi.org/10.1016/0360-1285(89)90017-8

[5] Frigo, Stefano, and Roberto Gentili. "Analysis of the behaviour of a 4-stroke Si engine fuelled with ammonia and hydrogen." International Journal of Hydrogen Energy 38, no. 3 (2013): 1607-1615. https://doi.org/10.1016/i.ijhydene.2012.10.114

[6] Westlye, Fredrik R., Anders Ivarsson, and Jesper Schramm. "Experimental investigation of nitrogen based emissions from an ammonia fueled SI-engine." Fuel 111 (2013): 239-247. https://doi.org/10.1016/i.fuel.2013.03.055

[7] Ryu, Kyunghyun, George E. Zacharakis-Jutz, and Song-Charng Kong. "Effects of gaseous ammonia direct injection on performance characteristics of a spark-ignition engine." Applied energy 116 (2014): 206-215. https://doi.org/10.1016/i.apenergy.2013.11.067

[8] Reiter, Aaron J., and Song-Charng Kong. "Demonstration of compression-ignition engine combustion using ammonia in reducing greenhouse gas emissions." Energy \& Fuels 22, no. 5 (2008): 2963-2971. https://doi.org/10.1021/ef800140f

[9] Gill, S. S., G. S. Chatha, A. Tsolakis, Stanislaw E. Golunski, and A. P. E. York. "Assessing the effects of partially decarbonising a diesel engine by co-fuelling with dissociated ammonia." International journal of hydrogen energy 37, no. 7 (2012): 6074-6083. https://doi.org/10.1016/j.ijhydene.2011.12.137

[10] Hogerwaard, Janette, and Ibrahim Dincer. "Comparative efficiency and environmental impact assessments of a hydrogen assisted hybrid locomotive." International Journal of Hydrogen Energy 41, no. 16 (2016): 6894-6904. https://doi.org/10.1016/j.ijhydene.2016.01.118 
[11] Hayakawa, Akihiro, Yoshiyuki Arakawa, Rentaro Mimoto, KD Kunkuma A. Somarathne, Taku Kudo, and Hideaki Kobayashi. "Experimental investigation of stabilization and emission characteristics of ammonia/air premixed flames in a swirl combustor." International Journal of Hydrogen Energy 42, no. 19 (2017): 14010-14018. https://doi.org/10.1016/i.ijhydene.2017.01.046

[12] Somarathne, Kapuruge Don Kunkuma Amila, Akihiro Hayakawa, and Hideaki Kobayashi. "Numerical investigation on the combustion characteristics of turbulent premixed ammonia/air flames stabilized by a swirl burner." Journal of Fluid Science and Technology 11, no. 4 (2016): JFST0026-JFST0026. https://doi.org/10.1299/ifst.2016jfst0026

[13] K.D.K.A. Somarathne, S. Hatakeyama, A. Hayakawa, and H. Kobayashi. "Numerical investigation on the emission reduction characteristics of the turbulent premixed ammonia/air premixed flames stabilized by a swirl burner." Proc Jpn Heat Transf Sympo, 53 (2016): 212.

[14] Valera-Medina, Agustin, Richard Marsh, Jon Runyon, Daniel Pugh, Paul Beasley, Timothy Hughes, and Phil Bowen. "Ammonia-methane combustion in tangential swirl burners for gas turbine power generation." Applied Energy 185 (2017): 1362-1371. https://doi.org/10.1016/i.apenergy.2016.02.073

[15] Kurata, Osamu, Norihiko Iki, Takayuki Matsunuma, Takahiro Inoue, Taku Tsujimura, Hirohide Furutani, Hideaki Kobayashi, and Akihiro Hayakawa. "Performances and emission characteristics of NH3-air and NH3CH4-air combustion gas-turbine power generations." Proceedings of the Combustion Institute 36, no. 3 (2017): 3351-3359. https://doi.org/10.1016/i.proci.2016.07.088

[16] KURATA, Osamu, Norihiko IKI, Takayuki MATSUNUMA, Takahiro INOUE, Masato SUZUKI, Taku TSUJIMURA, and Hirohide FURUTANI. "ICOPE-15-1139 Power generation by a micro gas turbine firing kerosene and ammonia." In The Proceedings of the International Conference on Power Engineering (ICOPE) 2015.12, pp. _ICOPE-15. The Japan Society of Mechanical Engineers, 2015. https://doi.org/10.1299/jsmeicope.2015.12. ICOPE-15- 96

[17] Ministry of Environment. Government of Japan. "Regulatory measures against air pollutants emitted from factories and business sites and the outline of regulation-emission standards for soot and dust and NOx." 1998.

[18] Duynslaegher, Catherine, Hervé Jeanmart, and Jacques Vandooren. "Ammonia combustion at elevated pressure and temperature conditions." Fuel 89, no. 11 (2010): 3540-3545. https://doi.org/10.1016/i.fuel.2010.06.008

[19] Hayakawa, Akihiro, Takashi Goto, Rentaro Mimoto, Taku Kudo, and Hideaki Kobayashi. "NO formation/reduction mechanisms of ammonia/air premixed flames at various equivalence ratios and pressures." Mechanical Engineering Journal (2015): 14-00402. https://doi.org/10.1299/mej.14-00402

[20] Hayakawa, Akihiro, Takashi Goto, Rentaro Mimoto, Yoshiyuki Arakawa, Taku Kudo, and Hideaki Kobayashi. "Laminar burning velocity and Markstein length of ammonia/air premixed flames at various pressures." Fuel 159 (2015): 98-106. https://doi.org/10.1016/j.fuel.2015.06.070

[21] Konnov, A. A. "Implementation of the NCN pathway of prompt-NO formation in the detailed reaction mechanism." Combustion and Flame 156, no. $11 \quad$ (2009): $2093-2105$. https://doi.org/10.1016/i.combustflame.2009.03.016

[22] Tian, Zhenyu, Yuyang Li, Lidong Zhang, Peter Glarborg, and Fei Qi. "An experimental and kinetic modeling study of premixed NH3/CH4/O2/Ar flames at low pressure." Combustion and Flame 156, no. 7 (2009): 1413-1426. https://doi.org/10.1016/i.combustflame.2009.03.005

[23] Mendiara, Teresa, and Peter Glarborg. "Ammonia chemistry in oxy-fuel combustion of methane." Combustion and Flame 156, no. 10 (2009): 1937-1949. https://doi.org/10.1016/j.combustflame.2009.07.006

[24] Duynslaegher, Catherine, Francesco Contino, Jacques Vandooren, and Hervé Jeanmart. "Modeling of ammonia combustion at low pressure." Combustion and Flame 159, no. 9 (2012): $2799-2805$. https://doi.org/10.1016/i.combustflame.2012.06.003

[25] Dagaut, Philippe, Peter Glarborg, and Maria U. Alzueta. "The oxidation of hydrogen cyanide and related chemistry." Progress in Energy and Combustion Science 34, no. 1 (2008): 1-46. https://doi.org/10.1016/i.pecs.2007.02.004

[26] Song, Yu, Hamid Hashemi, Jakob Munkholt Christensen, Chun Zou, Paul Marshall, and Peter Glarborg. "Ammonia oxidation at high pressure and intermediate temperatures." Fuel 181 (2016): 358-365. https://doi.org/10.1016/j.fuel.2016.04.100

[27] Klippenstein, Stephen J., Lawrence B. Harding, Peter Glarborg, and James A. Miller. "The role of NNH in NO formation and control." Combustion and Flame 158, no. $4 \quad$ (2011): $774-789$. https://doi.org/10.1016/j.combustflame.2010.12.013

[28] Okafor, Ekenechukwu C., Yuji Naito, Sophie Colson, Akinori Ichikawa, Taku Kudo, Akihiro Hayakawa, and Hideaki Kobayashi. "Experimental and numerical study of the laminar burning velocity of CH4-NH3-air premixed flames." Combustion and flame 187 (2018): 185-198. https://doi.org/10.1016/j.combustflame.2017.09.002

[29] Herbon, John T., Ronald K. Hanson, David M. Golden, and Craig T. Bowman. "A shock tube study of the enthalpy of formation of OH." Proceedings of the Combustion Institute 29, no. 1 (2002): 1201-1208. https://doi.org/10.1016/S1540-7489(02)80149-3 
[30] Otomo, Junichiro, Mitsuo Koshi, Teruo Mitsumori, Hiroshi Iwasaki, and Koichi Yamada. "Chemical kinetic modeling of ammonia oxidation with improved reaction mechanism for ammonia/air and ammonia/hydrogen/air combustion." International Journal of Hydrogen Energy 43, no. 5 (2018): 3004-3014. https://doi.org/10.1016/i.ijhydene.2017.12.066

[31] Glarborg, Peter, James A. Miller, Branko Ruscic, and Stephen J. Klippenstein. "Modeling nitrogen chemistry in combustion." Progress in Energy and Combustion Science $67 \quad$ (2018): 31-68. https://doi.org/10.1016/i.pecs.2018.01.002

[32] Miller, James A., Mitchell D. Smooke, Robert M. Green, and Robert J. Kee. "Kinetic modeling of the oxidation of ammonia in flames." Combustion Science and Technology 34, no. 1-6 (1983): 149-176. https://doi.org/10.1080/00102208308923691

[33] Okafor, Ekenechukwu Chijioke, Yuji Naito, Sophie Colson, Akinori Ichikawa, Taku Kudo, Akihiro Hayakawa, and Hideaki Kobayashi. "Measurement and modelling of the laminar burning velocity of methane-ammonia-air flames at high pressures using a reduced reaction mechanism." Combustion and Flame 204 (2019): 162-175. https://doi.org/10.1016/i.combustflame.2019.03.008

[34] Xiao, Hua, Agustin Valera-Medina, and Philip J. Bowen. "Modeling combustion of ammonia/hydrogen fuel blends under gas turbine conditions." Energy \& Fuels 31, no. 8 (2017): 8631-8642. https://doi.org/10.1021/acs.energyfuels.7b00709

[35] Taib, Norhidayah Mat, Mohd Radzi Abu Mansor, and Wan Mohd Faizal Wan Mahmood. "Simulation of Hydrogen Fuel Combustion in Neon-oxygen Circulated Compression Ignition Engine." Journal of Advanced Research in Numerical Heat Transfer 3, no. 1 (2020): 25-36.

[36] Yuze, S. U. N., C. A. I. Tao, Mohammad SHAHSAVARI, S. U. N. Dakun, S. U. N. Xiaofeng, Z. H. A. O. Dan, and W. A. N. G. Bing. "RANS simulations on combustion and emission characteristics of a premixed NH3/H2 swirling flame with reduced chemical kinetic modeltable 1." Chinese Journal of Aeronautics (2021).

[37] Franco, Miguel C., Rodolfo C. Rocha, Mário Costa, and Mohamed Yehia. "Characteristics of NH3/H2/air flames in a combustor fired by a swirl and bluff-body stabilized burner." Proceedings of the Combustion Institute 38, no. 4 (2021): 5129-5138. https://doi.org/10.1016/i.proci.2020.06.141

[38] CFX-Solver, A. N. S. Y. S. "Theory guide." Release I/ (2006).

[39] Poinsot, Thierry, and Denis Veynante. Theoretical and numerical combustion. RT Edwards, Inc., 2005.

[40] Zimont, V., Wolfgang Polifke, Marco Bettelini, and Wolfgang Weisenstein. "An efficient computational model for premixed turbulent combustion at high Reynolds numbers based on a turbulent flame speed closure." (1998): 526 532. https://doi.org/10.1115/1.2818178

[41] Zimont, Vladimir L. "Gas premixed combustion at high turbulence. Turbulent flame closure combustion model." Experimental thermal and fluid science 21, no. 1-3 (2000): 179-186. https://doi.org/10.1016/S08941777(99)00069-2

[42] Yehia, M. A., and M. A. Abdel-Raheem. "Modelling of flammable fuels in small and large scale turbulent environments." Fuel 266 (2020): 117110. https://doi.org/10.1016/j.fuel.2020.117110

[43] Takizawa, Kenji, Akifumi Takahashi, Kazuaki Tokuhashi, Shigeo Kondo, and Akira Sekiya. "Burning velocity measurements of nitrogen-containing compounds." Journal of hazardous materials 155, no. 1-2 (2008): 144-152. https://doi.org/10.1016/j.jhazmat.2007.11.089

[44] Pfahl, U. J., M. C. Ross, J. E. Shepherd, K. O. Pasamehmetoglu, and C. Unal. "Flammability limits, ignition energy, and flame speeds in H2-CH4-NH3-N2O-O2-N2 mixtures." Combustion and Flame 123, no. 1-2 (2000): $140-158$. https://doi.org/10.1016/S0010-2180(00)00152-8

[45] Zakaznov, V. F., L. A. Kursheva, and Z. I. Fedina. "Determination of normal flame velocity and critical diameter of flame extinction in ammonia-air mixture." Combustion, Explosion and Shock Waves 14, no. 6 (1978): $710-713$. https://doi.org/10.1007/BF00786097

[46] Han, Xinlu, Zhihua Wang, Mario Costa, Zhiwei Sun, Yong He, and Kefa Cen. "Experimental and kinetic modeling study of laminar burning velocities of $\mathrm{NH} 3$ /air, $\mathrm{NH} 3 / \mathrm{H} 2$ /air, $\mathrm{NH} 3 / \mathrm{CO} /$ air and $\mathrm{NH} 3 / \mathrm{CH} 4 /$ air premixed flames." Combustion and Flame 206 (2019): 214-226. https://doi.org/10.1016/j.combustflame.2019.05.003

[47] Göttgens, J., F. Mauss, and N. Peters. "Analytic approximations of burning velocities and flame thicknesses of lean hydrogen, methane, ethylene, ethane, acetylene, and propane flames." In Symposium (International) on Combustion, vol. 24, no. 1, pp. 129-135. Elsevier, 1992. https://doi.org/10.1016/S0082-0784(06)80020-2

[48] Fluent, A. N. S. Y. S. "Fluent 14.0 user's guide." ANSYS FLUENT Inc (2011).

[49] Chterev, I., C. W. Foley, D. Foti, S. Kostka, A. W. Caswell, N. Jiang, A. Lynch et al. "Flame and flow topologies in an annular swirling flow." Combustion Science and Technology 186, no. 8 (2014): 1041-1074. https://doi.org/10.1080/00102202.2014.882916 
[50] Yehia, Mohamed, Fawzy Abdel-Aziz, and H. Haridy. "Numerical analyis of ammonia/hydrogen flames in a swirl and bluff-body stabilized burner." Egyptian Journal for Engineering Sciences and Technology 29, no. EIJEST, Vol. 29, 2020 (2020): 28-42. https://doi.org/10.21608/eijest.2020.97322 